THURSDAY, AUGUST 3r, I87I

\section{ON THE VARIOUS TINTS OF FOLIAGE}

\section{A LTHOUGH we cannot yet say-}

Far, far o'er bill and dale green woods are changing, Autumn her many hues slowly arranging,

still it may be interesting to put together certain facts with reference to the tints of foliage which have recently been acquired to science.

Up to the present time I have been able to distinguish several dozen colouring matters in the leaves of different plants, and far more in the petals and fruits, and no doubt further inquiry will very greatly increase this number. The subject would, therefore, be quite unmanageable, if we could not divide them into well-marked groups by means of their optical characters. This is still more important when, as on the present occasion, it is desirable to give a condensed summary of the leadir.g facts. I shall, therefore, not attempt to describe the individual colouring matters, or to explain how they may be distinguished or identified by means of their spectra, either in their natural state or after being acted on by re-agents; but merely point out the general relations of the various groups, and refer to my published papers for illustrations of the methods employed in the inquiry.* The colours of these groups are not only related to one another optically and chemically, but also have a very similar connection with the growth of the plants, and thus it is possible to give a general explanation of the very various tints of foliage, without entering into technical details. For a more complete account, I beg to refer to a paper on this subject, just published in the July number of the Quarterly Fournal of Microscopical Science.

One of the chief difficulties in studying the colours met with in plants is, that they are often mixtures of quite distinct colouring matters. Sometimes these may be easily separated, for one may be soluble, and the other insoluble, in such reagents as water, alcohol, ether, or bisulphide of carbon; but in many cases they are so closely related, that anything like a complete separation is perhaps impossible ; even then, however, it may be possible so to effect a partial separation, that the presence of two different substances may be recognised, and with proper care a very good opinion may be formed as to their general properties. Nature, also, herself often assists us in this inquiry, for different plants, or the same in different states, may furnish particular colouring matters comparatively pure, or so variably mixed that the character of the mixture may be recognised.

For the purposes of the subject before us, I have found it desirable to divide the different colouring matters into the following groups :-

1. The Chlorophyll group is distinguished by being insoluble in water, but soluble in alcohol and in bisulphide of carbon. There are three or four species, giving wellmarked spectra, with several narrow, dark, absorption-

* Proceedings of the Royal Society, vol. xv., p. 433 (Philosophical Magrzine, vol. xxxiv., 1867, p. 144); Quarterly Fonrncal of Microscopical Scicnce, vol. ix., 1869 , pp. 43 and 358 ; Monthly Microscopical Fontral, vol. iii., r87o, p. 229 ; Quarterly Foumbal of Science, new ser., vol. i., 1870, p. 64. VoL, IV. bands, one or more of which occur at the red end. The mixed chlorophyll of ordinary green leaves may be obtained in a tolerably satisfactory state by heating in alcohol dark green holly leaves, previously crushed so as to insure rapid solution, and then, when cold, agitating in a test tube with bisulphide of carbon. This sinks to the bottom, holding nearly the whole of the dark green chlorophyll in solution, whilst nearly all the xanthophyll remains dissolved in the alcohol. Leaves having an acid juice must not be used, for that would change the normal chlorophyll into another modification, nor should the solution be left long in contact with them, for then the separation is much less perfect.

2. The Xanthophyll group also contains several distinct species, but only two are common in leaves, one being more, and the other less, orange. They are characterised by being insoluble in water, but soluble in alcohol and in bisulphide of carbon; and when dissolved in this latter their spectra show two not very distinct absorption-bands at the blue end; but the red, yellow, and yellow-green rays are freely transmitted. They may be obtained from yellow leaves, by the use of alcohol and bisulphide of carbon.

3. The Erythrophyll group comprises a number of colours soluble in water, in alcohol, and in ether, but insoluble in bisulphide of carbon. Those met with in leaves are more or less purple, made bluer by alkalis, and redder by acids; and thus sometimes plants containing the same kind may vary more in tint, owing to a variation in the amount of free acid, than others coloured by entirely different kinds. The erythrophyll may be obtained, free from chlorophyll and xanthophyll, by heating the leaves in alcohol, evaporating to dryness, redissolving in water, filtering, and evaporating at a gentle heat; but, on the whole, it is better to digest the leaves for a day or so in sufficient cold ether to dissolve all the contained water, and then to agitate with water, which subsides to the bottom, with nearly all the erythrophyll in solution, but mixed with more or less of the colours of the following group. There are many species of erythrophyll, some of which have very interesting botanical relationships, being so far found only in particular classes of plants.

4. The Chrysotannin group contains a considerable number of yellow colours, some so pale as to be nearly colourless, and others of a fine, dark, golden yellow. They are soluble in water, in alcohol, and in ether, but not in bisulphide of carbon. Their spectra show a variable amount of absorption at the blue end, usually with no bands when in their natural state, but sometimes with one or more sufficiently distinct when they are oxidised. They may be obtained free from chlorophyll and ranthophyll by processes similar to those made use of in the case of erythrophyll, and leaves should always be selected which are as free as possible from colours of that group. Some of the chrysotannin colours strike a dark colour with ferric salts, and constitute the tannic acid sub-group, of which there are at least six different kinds, whereas others do not give any such reaction, and constitute the chrysophyll sub-group. In both sub-groups the intensity of colour is usually greatly increased by partial oxidisation, and they are thus altered in to colours of the following group.

5. The Phaiophyll group comprises a number of more 
or less brown colours, insoluble in bisulphide of carbon, and of very variable solubility in water or alcohol. The spectra show strong absorption at the blue end, extending over the green, often the red is very dull, and sometimes there are definite absorption bands, when the solution is acid, neutral, or alkaline. On the whole they are in that state of oxidisation which has a maximum intensity of colour, and are simply decolourised by further oxidisation.

The very numerous tints of foliage depend almost entirely on the relative and absolute amount of the various colours of these different groups, but much remains to be learned before we can explain all their relationships. The colour of green leaves is mainly due to a mixture of chlorophyll and xanthophyll and the variation in the relative and absolute amount of these easily accounts for the darker and brighter greens. The tints are also much modified by the pressure of colours of the erythrophyll group, which, according to circumstances, may give rise to lighter or darker browns, approaching to black, or to reds. Healthy unchanged leaves also contain various substances belonging to the chrysotannin group, but in many cases when these belong to the more typical kinds of tannic acid, their colour is so faint that they have little or no influence on the general appearance of the leaves.

The relation of these groups to one another is still somewhat obscure. There are facts which seem to indicate that chlorophyll may in some cases pass into xanthophyll by oxidisation, and xanthophyll into chlorophyll by deoxidisation, but neither point can be considered to be established. There is manifestly some connection between the formation of chlorophyll and erythrophyll; and those conditions which are favourable to the production of one are unfavourable to the development of the other. In the present state of our knowledge it seems most probable that chlorophyll is formed when the vital functions of the leaves are very active, and erythrophyll when they are less active but not destroyed. Exposure to light also appears to be necessary, and we often see rough natural photographs of superjacent leaves produced in this manner. As I have already said there are several different kinds of erythrophyll, giving very different spectra, but the most prevalent are two which are related to each other in an interesting manner. One of these is more especially found in very young leaves, and when slightly oxidised artificially it passes into the other. This more oxidised kind is that found in the greater number of leaves which are red in autumn. Both are completely decolourised by further oxidisation, and most probably this occurs in leaves themselves when their red colour is lost. Since many contain erythrophyll in early spring and lose it as the season advances, whilst it still continues to be present in the leaf-stalks, I am much inclined to believe that its disappearance is due to the ozonised oxygen given off from the chlorophyll, which is developed to so much greater an extent in the leaves than in the stalks, and that its reappearance in autumn in many leaves is characteristic of the period when they are not dead but have more or less ceased to give off ozone.

On the approach of autumn, before the leaves have withered, we have thus in the foliage of different.plants an exceedingly variable mixture of chlorophyll, xanthophyll, and erythrophyll, with the different members of the chrysotannin group; and it is to the changes which occur in some or all of these substances that the very variable tints of autumn are due. The most striking of these depend on the alteration of the chlorophyll. So long as it remains green the production of bright reds and yellows is impossible, but when it disappears the yellow colour of the xanthophyil is made apparent ; and, if much erythrophyll is present, or contemporaneously developed, its colour, combined with this yellow, gives rise to scarlet or red. In many cases, however, the chlorophyll does not disappear, but is changed into the dark olive modification, easily prepared artificially by the action of acids on the more green, and when this is present, only dull and unattractive tints can be produced. We may thus easily understand why the special tints of early autumn are yellows and reds, or dull and dark greens. In these changes the various pale yellow substances of the chrysotannin group remain comparatively unaltered, and even sometimes increase in quantity ; but they soon pass into the much darker redbrowns of the phaiophyll group, whilst the erythrophyll fades ; and thus later in the autumn the most striking tints are the brighter or duller browns, characteristic of the different kinds of plants or trees.

As already named there are many different species of colouring matters belonging to the chrysotannin group, both of those which are, and of those which are not, closely related to the more typical kinds of tannic acid. So far I have not been able to ascertain whether there is any one particular artificial oxidising process which will in each case give rise to the exact products naturally formed in the leaves themselves; but on the whole there is such a close correspondence between them that we cannot hesitate in concluding that the rich brown tints of autumn are mainly due to the oxidisation of the previouslyexisting more or less pale yellow colour of the chrysotannin group-a conclusion fully borne out by various independent facts. The difference in kind of tannic acid, and the absence or presence of any considerable amount of a chrysophyll substance, explains in a very satisfactory manner the difference in the tint of the leaves of different trees. Thus, for example, the quinotannic acid found in a comparatively pure state in the yellow leaves of the beech is changed by oxidisation into the fine red-brown colour of those leaves at a later period. This kind of tannic acid also occurs in the elm, but is there mixed with more or less of a chrysophyll, which turns to a duller brown; and thus we find the leaves of different elm-trees vary in tint, and are often of very dull brown colour. The leaves of the oak and Spanish chesnut contain gallo-tannic acid, and this, when oxidised, gives rise to a dull tint, like that seen in the faded leaves of those trees; and similar principles hold good in other cases.

As far as we are able to judge from the various facts described above, we must look upon the more characteristic tints of the foliage of early spring as evidence of the not yet matured vital powers of the plant. In summer the deeper and clearer greens are evidence of full vigour and high vitality, which not only resists but also actually overcomes the powerful affinity of oxygen. Later on the vital powers are diminished, and partial changes occur, but the affinity of the oxygen of the atmosphere is nearly balanced by the 
weakened but not destroyed vitality. At this stage the beautiful red and yellow tints are developed, which produce such a fine effect in certain kinds of scenery. Then comes more complete death, when the affinity of oxygen acts without any opposition, and the various brown tints of later autumn make their appearance, due to changes which we can imitate in our experiments with dead compounds. This may not be a pleasing way of viewing an otherwise charming subject, but I think we must all admit that it is substantially true.

\section{H. C. SORBY}

\section{HUMAN ANATOMY AND PHYSIOLOGY}

The Physiological Anatomy and Physiology of Man. By Robert B. Todd, William Bowman, and Lionel S. Beale. A new edition by the last-named author. Part 2 of Vol. i. (Longmans and Co., $187 \mathrm{r}$ )

THIS part corresponds to the third, fourth, and fifth chapters of the last edition; it is now divided into four chapters, one of which is devoted to a general consideration of the properties of tissue, and the others contain detailed accounts of the connective, cartilaginous, osseous, and adipose varieties. Dr. Beale seems to have spared no time or trouble upon the present part, which has been carefully revised throughout; a considerable amount of new matter has been added, and many parts, especially those relating to the development of the different tissues, have been entirely re-written.

The chapter on the forms of connective tissue is very full and complete, and compares very favourably with that in the last edition; descriptions of several wellmarked varieties, which were before omitted, being now introduced, such as those occurring in the Whartonian jelly, the vitreous humour, and the cornea. With respect to yellow elastic tissue, Dr. Beale states that the fibres, usually considered to belong to it, which are found in tendons, and resist the action of acetic acid, are not of elastic nature at all, but are merely imperfectly-formed white fibrous tissue; and in his account of areolar tissue he strongly contests one of the most generally-received pathological doctrines of the day, that which supposes in many cases of degeneration that the interstitial areolar tissue of the organ is the active agent, becoming hypertrophied, and then contracting and compressing the structures in its meshes. Dr. Beale considers, on the contrary, that in most cases the areolar tissue is quite passive, and that the phenomena ascribed to it are really produced by the rapid multiplication of parts of white blood corpuscles which have passed through the walls of the blood vessels.

In his account of cartilage Dr. Beale dissents from the opinion held by some, that the capsule of a cartilage cell differs from the matrix in its origin and nature; he points out that in some cases there is no matrix, in others no cell-wall can be demonstrated as distinct from the matrix; and again, in others the capsule passes gradually into the matrix; and maintains that the matrix when present is entirely formed of old capsules, and is not developed independently of the cells. Fibro-cartilage and elastic cartilage are both well described; no mention at all of the latter form was made in the previous editions.

The chapter on bone contains a good account of its histological structure, but is chiefly interesting from the views put forward as to the mode of origin of the canaliculi. Virchow states that they are formed by the deposition of calcareous matter round processes radiating from corpuscles contained in the lacuna, while Kölliker thinks they are formed by resorption after the lacuna has been entirely surrounded by calcareous matter. Dr. Beale differs from both-he says the bone corpuscles of the lacuna have frequently no processes, and that when processes are present they are always much shorter and much less numerous than the canaliculi, and he points out that the formation of these little channels begins at their distal end, not at the end next the lacuna, as has been supposed; his own view is that in an early stage of the development of bone, it is all permeable to nutrient fluids, but that as calcareous matter is deposited this permeability gets restricted to constantly narrowing channels, which ultimately remain as the canaliculi, and are at first filled with soft matter (cartilage or membrane), which in fully formed bone dries and shrivels up, leaving the canaliculi as true tubes.

The concluding chapter, that on adipose tissue, is on the whole good, but in the account of its histological structure the impression is conveyed that an adult fat cell consists merely of an envelope containing oily matterno mention being made of the fact that by proper treatment a nucleus also can be almost always demonstrated. Dr. Beale considers that the fatty matter contained in the cell is formed by the degeneration of the mass of "bioplasm," or "germinal matter," of which it was once entirely composed.

The part is illustrated by a large number of very good figures, and several full-page plates.

\section{OUR BOOK SHELF}

Elementary Treatise on Natural Philosophy. By A. Privat Deschanel. Translated and edited by Prof. Everett, M.A., D.C.L., \&c., Professor of Natural Philosophy, Queen's College, Belfast. In Four Parts; Part 2.-Heat. (London: Blackie and Son.)

THIS work is intended to be an elementary treatise on the science of Heat. The remarkably fine engravings that embellish it throughout, give it an air of reality which, uns fortunately, is not generally possessed by English scientific books. Still, some of the original engravings might have been improved; for example, figs. $223,240,245$, and 264 are peculiar, and do not represent what is likely to be seen in the laboratory. Having said this much in favour of Prof. Everett's translation, we cannot avoid making some unfavourable criticisms. We decidedly object to the numerous formulæ and equations which may almost be said to disfigure many of the pages; they are not sufficiently explained for a popular work, and might have been more compressed if intended for advanced scientific students. And seeing that formulæ and explanations usually vary inversely as each other within the same volume, we should have been pleased-indeed, we expected - to find as many of the former eliminated as possible. This expectation was occasioned by the translator himself, who complained that oftentimes we are confronted with " unexplained formulæ, which burden the memory without cultivating the understanding." Can Prof. Everett assert that he has explained the formula on page 362 of Part 2 ? Has he not rather fallen into the very error which he so ably deplores in his preface; failing to see amid V, KT, and other algebraic mystifications, that his $\mathrm{H}$ and $\mathrm{h}$ are 